\title{
Managing mitral regurgitation: focus on the MitraClip device
}

This article was published in the following Dove Press journal:

Medical Devices: Evidence and Research

12 April 2016

Number of times this article has been viewed

\author{
J Trent Magruder' \\ Todd C Crawford' \\ Joshua C Grimm' \\ Joseph L Fredi \\ Ashish S Shah ${ }^{3}$ \\ 'Division of Cardiac Surgery, \\ Johns Hopkins University School \\ of Medicine, Baltimore, MD, \\ ${ }^{2}$ Department of Medicine, Division \\ of Cardiovascular Medicine, \\ Vanderbilt University Medical Center, \\ ${ }^{3}$ Department of Cardiac Surgery, \\ Vanderbilt University School of \\ Medicine, Nashville, TN, USA
}

\begin{abstract}
Based on the principle of surgical edge-to-edge mitral valve repair (MVR), the MitraClip percutaneous MVR technique has emerged as a minimally invasive option for MVR. This catheter-based system has been widely demonstrated to be safe, although inferior to surgical MVR. Studies examining patients with $\geq 3+$ mitral regurgitation (MR) show that, for all patients treated, freedom from death, surgery, or $M R \geq 3+$ is in the $75 \%-80 \%$ range 1 year following MitraClip implantation. Despite its inferiority to surgical therapy, in high-risk surgical patients, data suggest that the MitraClip system can be employed safely and that it can result in symptomatic improvement in the majority of patients, while not precluding future surgical options. MitraClip therapy also appears to reduce heart failure readmissions in the high-risk cohort, which may lead to an economic benefit. Ongoing study is needed to clarify the impact of percutaneous mitral valve clipping on long-term survival in high-risk populations, as well as its role in other patient populations, such as those with functional MR.
\end{abstract}

Keywords: mitral clips, mitral regurgitation, cardiac surgery, percutaneous, transcatheter

\section{Introduction}

Mitral regurgitation (MR) continues to impose significant morbidity and mortality on patients. Since even asymptomatic MR typically progresses to left ventricular dilatation, left ventricular failure, worsening MR, and eventual symptom onset, surgical therapy has traditionally been advocated to break this cycle. However, though effective, even mitral valve repair (MVR), as opposed to replacement, has been associated with firsttime operative mortality rates in the $2 \%$ range, and reoperative mortality rates as high as $8 \% .{ }^{1}$ Accordingly, the MitraClip system has emerged as a transcatheter method of treating MR while avoiding the adverse effects associated with cardiopulmonary bypass and open cardiac surgery.

\section{History}

The history of the MitraClip begins with advances made in the surgical treatment of MR. For at least two decades, it has become clear that for most patients, mitral repair (rather than replacement) provides superior outcomes at lower risk. ${ }^{2,3}$ Traditionally, repair has been performed via ring annuloplasty based on the seminal work of Dr Carpentier and others, ${ }^{4,5}$ but other techniques have been proposed (Figure 1). The MitraClip technology draws on experience with the edge-to-edge MVR, first described by Dr Alfieri in the 1990s. ${ }^{6}$ This technique, first employed in patients with single or bileaflet prolapse, involves the placement of suture to anchor the free edge
Correspondence: Ashish S Shah Department of Cardiac Surgery, Vanderbilt University School of Medicine, I2I5 2 Ist Avenue South, Suite 5025, Nashville, TN 37232, USA

Tel + I 6153437363

Email ashish.s.shah@vanderbilt.edu
Medical Devices: Evidence and Research 2016:9 53-60

(c) (1) (8) ( ) 2016 Magruder et al. This work is published and licensed by Dove Medical Press Limited. The full terms of this license are avalabble at https://wwr.dovereress.com/ cc. work you hereby accept the Terms. Non-commercial uses of the work are permitted without any further permission from Dove Medical Press limited, provided the work is properly attributed. For permission for commercial use of this work, please see paragraphs 4.2 and 5 of our Terms (https://www.dovepress.com/terms.php).
Dovepress

http://dx.doi.org/1 0.2147/MDER.S86645

\section{3}



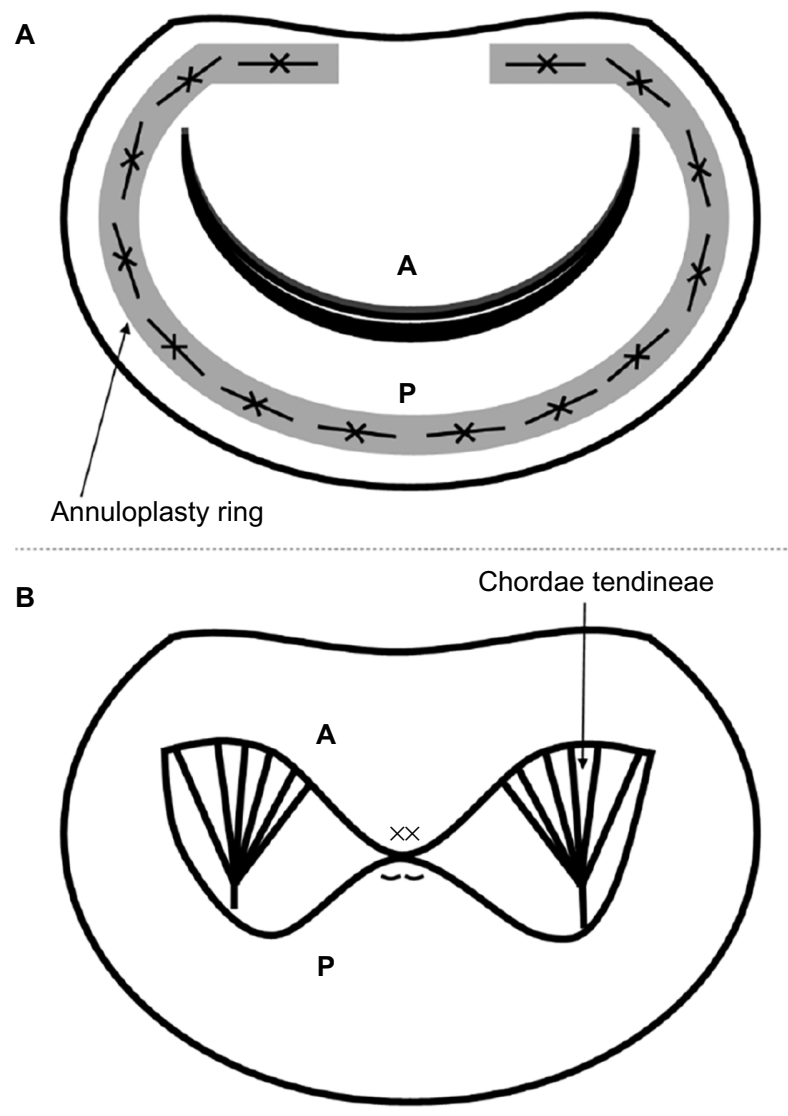

Figure I Schematic diagram of two methods of mitral valve repair.

Notes: (A) ring annuloplasty (gray shaded ring, secured with sutures). (B) Alfieri edge-to-edge repair (ie, mid-leaflet plication as shown with $\mathrm{Xs}$ to denote suture placement across both leaflets.

Abbreviations: A, anterior mitral leaflet; P, posterior mitral leaflet.

of the prolapsed leaflet to its corresponding opposite leaflet. Alfieri's simple method results in the creation of two valve orifices if prolapse occurs in the middle portion of a leaflet, or a smaller valve orifice should the lesion be pericommissural. ${ }^{7}$ This "double-orifice" technique omitted annuloplasty. In his original series, Alfieri documented rates of survival and freedom from reoperation to be above $90 \%$ over 5 years after MVR using his technique. ${ }^{6}$

Based on these findings, investigators at major academic institutions in concert with private industry (Evalve, Redwood City, CA, USA; later Abbot Vascular, Santa Clara, CA, USA) developed a transcatheter method of accomplishing reapproximation of the anterior and posterior mitral leaflets as a therapy for MR. This method was first described in adult pigs in $2003 .{ }^{8}$ The original device was inserted via the femoral vein and utilized a $24 \mathrm{Fr}$ guidewire to gain transseptal access to the left atrium (Figure 2A and B). The tip of this catheter was designed with a bidirectional steering mechanism so it can be positioned centrally above the mitral valve annulus. Once the delivery catheter is in position, a V-shaped clip is introduced while closed. The clip, which is polyester-covered and made of cobalt-chromium, spans about $4 \mathrm{~mm}$ when closed, and has a maximum arm excursion of about $20 \mathrm{~mm}$ when opened (Figure 2C). The clip is then opened and rotated in the left atrium so as to be perpendicular to the lines of leaflet coaptation, advanced into the left ventricle, and then retracted during systole to snare the anterior and posterior leaflets (Figure 2D). Importantly, the clip can be opened and closed repeatedly to ensure optimal positioning.

Early animal data using this technique were promising. In the first report of clip use in 14 adult pigs, a functional double-orifice valve was achieved in 12 animals. ${ }^{8}$ The clip failed to grasp the anterior leaflet in the remaining two animals, which the authors determined was due to incomplete opening of the clip prior to positioning. Following sacrifice, none of the animals exhibited significant injury to other cardiac structures. A subsequent study by the same investigators using the same animal model (but with direct left atrial access via thoracotomy instead of femoral vein access) demonstrated successful clip placement in all 21 animals utilized. ${ }^{9}$ After various survival points between 4 and 52 weeks, 20 of the 21 animals (96\%) had a double-orifice valve on necropsy. Adequate histopathologic evidence of healing and endothelialization were also noted in all animals except for two that developed endocarditis and required early euthanization.

\section{Current surgical techniques to address mitral regurgitation}

Consideration should be given to the current state of the art in open surgical therapy for MR. As mentioned earlier, the placement of a synthetic ring around the mitral annulus to improve leaflet coaptation was first recommended by Dr Carpentier and has since been shown to provide durable long-term relief from MR, with up to $90 \%$ of degenerative mitral valves able to be repaired in this fashion., ${ }^{4,5}, 10$ Ring annuloplasty, though, represents only one technique to address MR, which Dr Carpentier and various others have advocated. Isolated prolapse of the posterior leaflet, which can occur due to chordal rupture, can be addressed by triangular or quadrangular resection of the leaflet's central portion, with reapproximation to "tighten" it. However, care must be taken to not over-correct the defect, or systolic anterior motion of the anterior mitral valve leaflet into the outflow tract may result. ${ }^{11}$ Another method to address a prolapsing leaflet is the placement of artificial polytetrafluoroethylene (PTFE) neochordae "loops" between the leaflet and papillary muscle in order to pull a prolapsing leaflet downward and improve coaptation, and/or to replace ruptured papillary muscles or 
A

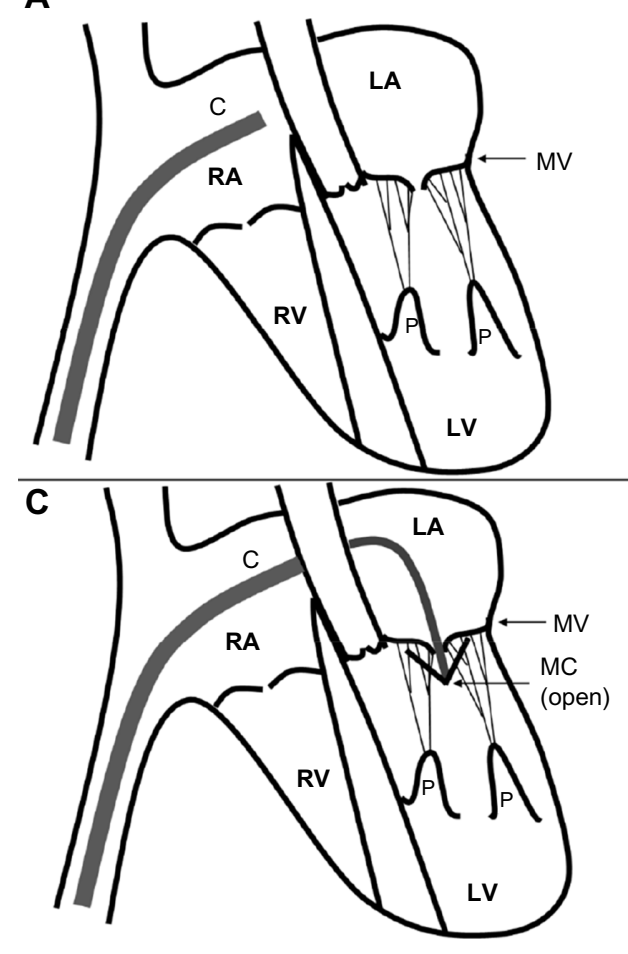

B

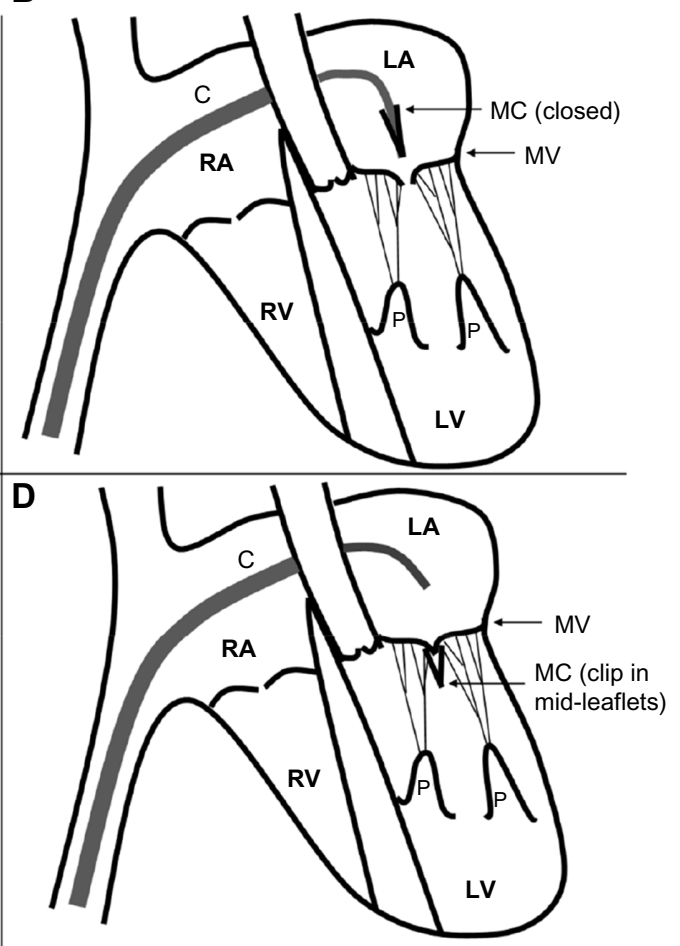

Figure 2 Schematic of MitraClip device insertion.

Notes: (A) Device inserted to right atrium, ready to cross atrial septum. (B) Septum traversed, and device curving inferiorly to pass through mitral orifice. (C) MitraClip in place to arrest leaflets. (D) Successful MitraClip capture of leaflets (clip shown closed so as to reapproximate mid-leaflets).

Abbreviations: C, MitraClip catheter; MC; MitraClip clip; LA, left atrium; LV, left ventricle; RA, right atrium; RV, right ventricle; MV, mitral valve; P, papillary muscles.

chordae tendineae. ${ }^{12,13}$ This method, which requires careful measurement to ensure appropriate length of the PTFE neochordae, has been demonstrated to be safe and effective on long-term follow-up as well. ${ }^{14,15}$ At least one randomized trial has shown that leaflet resection and PTFE neochordae placement have similar early and mid-term outcomes, ${ }^{16} \mathrm{a}$ finding echoed by other investigators. ${ }^{17,18}$

Newer technologies have led to less invasive approaches to utilize the same principles while minimizing the morbidity of open cardiac surgery. All of the above approaches today are often performed through a right lateral mini-thoracotomy or a conventional median sternotomy. With the introduction of the robotic surgery and the Da Vinci robotic system (Intuitive Surgical, Sunnyvale, CA, USA), MVR can be accomplished through five trocar ports in the right chest and peripheral cardiopulmonary bypass cannulation. Recent large series of robotic MVR performed at experienced centers suggests that this approach is safe and effective at least through mid-term follow-up. ${ }^{19-21}$

\section{Early results in man}

Based on these findings in animal models, a US Food and Drug Administration Investigational Device Exemption-approved phase I safety and feasibility trial was conducted: EVEREST I (Endovascular Valve Edge to Edge Repair Study). ${ }^{22}$ The trial enrolled 27 patients with at least moderate-to-severe MR $(\geq 3+)$, of whom 22 were discharged with clips in place. Three patients underwent the percutaneous procedure but did not have a clip left in place due to inadequate reduction of MR (and subsequently underwent elective MVR), while two other patients underwent elective MVR following device malfunctions. Of the 22 patients discharged with clips in place, 14 patients had MR $\leq 2+$ at 1 month; 13/14 patients maintained this improvement at 6 months. Freedom from MVR was $82 \%$ $(18 / 22)$ at 6 months. Freedom from 30-day major adverse events (MAEs) was $85 \%$, with one patient having a stroke and three patients experiencing clip detachment from one leaflet. It is worth noting that the study protocol was modified after the first ten patients to allow multiple clips to be implanted should MR only improve partially after implantation of a single clip; subsequent studies have shown that this technique is most useful in patient with a wide regurgitant jet (vena contracta $>7.5 \mathrm{~mm}$ ). ${ }^{23}$

A follow-up study, EVEREST II, analyzed 107 patients (including the original EVEREST I patients) in whom the MitraClip procedure was attempted. ${ }^{24,25}$ These patients either 
had symptoms or evidence of left ventricular dysfunction with $\mathrm{MR} \geq 3+$. By the investigators' definition of procedural success (MR $\leq 2+), 74 \%$ (79/107) patients underwent successful MitraClip placement. Substantial intraprocedural hemodynamic stability was observed for all patients. The composite primary endpoint of freedom from $\mathrm{MR}>2+$, surgery, or death was $66 \%$, with symptomatic improvement observed in $74 \%$ of patients. When examining only patients who underwent a successful procedure, 77\% achieved MR $\leq 2+$; 3-year survival was $90.1 \%$, and freedom from surgery was $76.3 \%$. Echocardiographically, at 12 months, annular diameter remained stable in patients with clips. Of note, however, 11 patients did not have a clip implanted due to MR $>2+$ intraprocedurally after the clip was placed (at which point the clip was removed intraprocedurally), while 17 patients had a clip implanted but still had MR $>2+$ postprocedure. Among the 32 patients who ended up having MVR following clip attempt, 25 had a planned repair, and 21 underwent successful repair - which the authors interpreted as indicating that clipping did not preclude surgical options. A subsequent analysis of the same 107 patients confirmed this finding. ${ }^{26}$

Of note, investigators did find evidence for a learning curve as interventionalists accumulated experience with the MitraClip device. In the 2009 EVEREST mid-term study, a decrease in procedure time (transseptal access to guidewire removal) from 231 to 90 minutes was noted over the study period. A group of German investigators similarly noted that decreases in safety events and increases in successful clip placement (ie, with reduction in MR to $\leq 2+$ ) over the course of the first 75 patients receiving MitraClips. ${ }^{27}$

\section{Accumulating evidence}

In 2011, the first randomized trial comparing the MitraClip device to clipping versus standard MVR was published (Table 1). ${ }^{28}$ Two hundred and seventy-nine patients with predominantly primary $\geq 3+\mathrm{MR}$ were randomized in a $2: 1$ ratio to undergo MitraClip implantation or conventional surgical MVR (either repair or replacement). The composite endpoint of freedom from death, surgery, or $>2+$ MR at 12 months was achieved in $55 \%$ of MitraClip patients versus $73 \%$ of surgery patients $(P=0.007)$; the principal driver of this difference was a $20 \%$ surgery rate in the MitraClip cohort versus a $2 \%$ reoperative rate in the de novo surgery cohort. Surgery patients experienced superior decreases in MR grade, with $76 \%$ demonstrating MR $\leq 1+$ compared to $43 \%$ of MitraClip patients. Notably, however, among percutaneous patients who experienced an improvement in MR grade immediately after the procedure, these improvements were durable through 24 months of follow-up. Both groups demonstrated similar symptomatic improvements, though surgery patients had a greater decrease in left ventricular end-diastolic volume than did MitraClip patients. MAEs were documented in only $15 \%$ of MitraClip patients versus $48 \%$ of surgery patients. However, the definition of MAEs in this trial included transfusion of $\geq 2$ units of blood; excluding this criterion, MAE rates did not differ significantly between groups. The authors concluded that though surgery appeared more effective in treating MR, percutaneous treatment was also effective and safer in a large number of patients and was associated with lower rates of MAEs.

Given the finding that MitraClips were inferior to surgery but still beneficial to some patients, and safer, a key question was whether or not the use of a MitraClip procedure affected options for surgical correction of MR. Indeed, this was examined in a subsequent study of EVEREST II patients. Of the 107 examined, 32 patients underwent subsequent surgery ( 23 of whom had at least one clip implanted). This study found that the overall MVR (as opposed to replacement) rate was comparable for patients undergoing MitraClip implantation versus de novo MVR. ${ }^{29}$ However, in $13.5 \%$ of patients studied, when a subsequent operation was required, replacement rather than repair had to be performed due to leaflet injury associated with the clip. Unfortunately, this study did not directly address whether the placement of two clips, as opposed to one, impacted the ability to repair the mitral valve during surgery. Small case reports suggest that repair is still possible even after the placement of more than one clip..$^{30,31}$

Subsequent studies have tended to confirm the EVEREST I and II results. In particular, several studies of "real-world" experience with the MitraClip system have been published with reasonable results. A large European study, the Amsterdam Center for Contemporary European Studies - A Two-Phase Observational Study of the MitraClip System in Europe (ACCESS-EU) prospective nonrandomized trial, found $81.8 \%$ survival at 1 year and $78.9 \%$ freedom from $\mathrm{MR} \geq 3+.^{32}$ Data from the Getting Reduction of Mitral Insufficiency by Percutaneous Clip Implantation (GRASP) registry at 30 days and 1 year show promising results: freedom from the same composite endpoint of death, surgery, or $\mathrm{MR} \geq 3+$ in $75.8 \%$ of 117 treated patients at 1 year (with no operations occurring), and a 3.4\% MAE rate at 30 days. ${ }^{33}$ These data also failed to show any differences in safety or outcomes when comparing patients with degenerative versus functional MR. A recent meta-analysis reviewing 16 studies 
Table I Summary of selected studies of percutaneous mitral valve clipping

\begin{tabular}{|c|c|c|c|c|c|c|c|}
\hline Study & Year & Patient population & $\mathbf{N}$ & $\begin{array}{l}\text { Acute } \\
\text { procedural } \\
\text { success (\%) }\end{array}$ & $\begin{array}{l}\text { 30-day } \\
\text { MAEs } \\
\text { (\%) }\end{array}$ & $\begin{array}{l}\text { I-year } \\
\text { survival } \\
(\%)\end{array}$ & $\begin{array}{l}\text { I-year freedom from } \\
\text { death/surgery/ } \\
M R \geq 3+\end{array}$ \\
\hline EVEREST $\mathrm{I}^{22}$ & 2005 & $M R \geq 3+$ & 27 & 88.9 & 15.0 & NR & NR \\
\hline EVEREST $\|^{24}$ & 2009 & $\begin{array}{l}M R \geq 3+\text { and symptoms or } \\
\text { evidence of } L V \text { dysfunction }\end{array}$ & 107 & 74.0 & 9.1 & 95.9 & $66.0 \%$ \\
\hline $\begin{array}{l}\text { EVEREST II } \\
(\text { NEJM RCT })^{28}\end{array}$ & 2011 & $\begin{array}{l}M R \geq 3+\text { and symptoms or } \\
\text { evidence of } L V \text { dysfunction }\end{array}$ & 279 & 77.0 & 15.0 & 94.0 & $55.0 \%$ \\
\hline EVEREST II HRS ${ }^{29}$ & 2012 & $\begin{array}{l}M R \geq 3+\text { and symptoms } \\
\text { and predicted surgical } \\
\text { mortality } \geq 12 \%\end{array}$ & 78 & 71.8 & 26.9 & 75.4 & $77.8 \%$ free from $M R \geq 3+$ \\
\hline ACCESS-EU ${ }^{32}$ & 2013 & $\begin{array}{l}\text { Symptomatic } M R \text {, or } \\
\text { asymptomatic } M R \geq 3+\end{array}$ & 567 & 91.0 & $\sim 10-15 ?$ & 81.8 & $78.9 \%$ free from $M R \geq 3+$ \\
\hline GRASP 33 & 2013 & $\begin{array}{l}M R \geq 3+\text { patients deemed } \\
\text { at high surgical risk }\end{array}$ & 117 & 100.0 & 4.3 & 86.0 & $75.8 \%$ \\
\hline $\begin{array}{l}\text { Vakil et al } \\
\text { meta-analysis }{ }^{34}\end{array}$ & 2014 & $M R \geq 3+$ & 2,980 & 91.4 & $\sim 10-15$ & 84.2 & $86.9 \%$ free from $M R \geq 3+$ \\
\hline $\begin{array}{l}\text { TRAMI } \\
(\text { Puls et al) })^{35}\end{array}$ & 2015 & $M R \geq 3+$ & 749 & 97.0 & $\sim 10-15$ & 79.7 & NR \\
\hline
\end{tabular}

Note: Citations are shown in superscript in the first column.

Abbreviations: EVEREST, Endovascular Valve Edge to Edge Repair Study; GRASP, Getting Reduction of Mitral Insufficiency by Percutaneous Clip Implantation; MR, mitral regurgitation; LV, left ventricle; MAEs, major adverse events; NR, not reported; HRS, high risk study; NEJM RCT, New England Journal of Medicine randomized controlled trial; TRAMI, Transcatheter Mitral Valve Interventions.

came to similar conclusions, documenting a low adverse event profile (with blood transfusions accounting for the majority of MAEs) and only $14.7 \%$ of patients demonstrating $\mathrm{MR} \geq 3+$ at 1 year. ${ }^{34}$ Most recently, in the largest series of MitraClip-treated patients published to date ( 749 patients with 1-year follow-up), data from the German transcatheter mitral valve interventions registry demonstrated 79.7\% 1-year survival among all patients (as opposed to EVEREST II, in which MR was predominantly primary in etiology), as well as a decreased rate of hospital readmission for heart failure. ${ }^{35}$ Unfortunately, this excellent study did not include echocardiographic follow-up at 1-year.

\section{MitraClip use in high-risk and other populations}

Given the perceived attractiveness of a percutaneous approach over MVR in high-risk patients, the MitraClip investigators published a study examining 1-year results of EVEREST II patients deemed at high surgical risk. ${ }^{36}$ This study was logical given the finding on subgroup analysis in EVEREST II that surgery and percutaneous clipping had equivalent outcomes for patients aged 70 and older. ${ }^{28}$ Patients selected had MR $\geq 3+$ as well as Society of Thoracic Surgeons predicted operative mortality rate of $\geq 12 \%$. In this High Risk Study, 78 patients were enrolled; 75 had a clip implanted and $75 \%(56 / 75)$ achieved MR $\leq 2+$. Eighty-nine percent of patients were New York Heart Association III/IV functional class preintervention; this improved to $74 \%$ being NYHA
I/II postclipping. (Though not available in this EVEREST cohort, a study of similar high-risk patients also demonstrated that these individuals experience marked declines in pro-brain natriuretic peptide at 6 and 12 months.) $)^{37}$ No patients received surgery over 12 months of follow-up, and $75.4 \%$ were alive at 1 year compared to $55.3 \%$ of patients in a retrospective comparator group with similar degrees of $\mathrm{MR}$ and predicted surgical risks managed medically. As with prior studies, favorable left ventricular remodeling was observed, and MAEs occurred in $26.9 \%$ of patients through 30 days ( $21 / 78 ; 14$ of these were blood transfusions $\geq 2$ units). A $45 \%$ reduction in hospitalization rates from congestive heart failure was also documented following successful MitraClip implantation (reduction to $\mathrm{MR} \leq 2+$ ) among surviving EVEREST High Risk Registry patients compared to matched controls. ${ }^{36,38}$ Given the poor natural history of these patients' disease, the authors concluded that MitraClip therapy was safe and effective in this high-risk population, particularly considering the absence of other viable therapeutic options. A similar analysis of very high-risk patients with euroSCORE $>20$ also found evidence for safety and feasibility in this patient population, with a majority of patients demonstrating clinical improvement. ${ }^{37}$ More recently, a meta-analysis of 12 prospective observational studies confirmed that in high-risk surgical patients, MitraClip implantation is safe and associated with 1-year survival rates in the range of $75 \%-90 \% .39$

An important question is whether or not MitraClip therapy in high-risk patients simply alleviates symptoms or actually 
improves survival. Data in surgical patients suggest that the presence of $\geq 1+\mathrm{MR}$ is associated with decreased survival following MVR, and even elimination of MR in high-risk surgical patients undergoing MVR has not been conclusively associated with improved survival. ${ }^{40,41}$ Additionally, as with the surgical Alfieri edge-to-edge MVR, the lack of an annuloplasty when employing the MitraClip may be problematic and explain the progression of MR in some patients. Data on the long-term results of MitraClip therapy in highrisk patients has yet to emerge.

The MitraClip has also been tested and shown to be safe and at least modestly beneficial in several other patient subpopulations. In addition to several trials underway in patients with functional MR (see later), one recent study of 60 patients treated with MitraClip compared to 60 patients managed medically revealed survival of $98.3 \%$ in the percutaneous therapy group compared to $89.7 \%$ in the MitraClip group at 1 year; at 3 years, these figures were $61.4 \%$ versus $34.9 \%$ $(P=0.007) .{ }^{42}$ Seventy-two percent of patients achieved MR $\leq 2+$ postprocedure and maintained it through 12 months of follow-up. Other patient populations studied include: patients with renal impairment (a strong predictor of early mortality $)^{43,44}$ and patients with $\geq 3+$ MR and left ventricular dyssynchrony nonresponsive to cardiac resynchronization therapy. ${ }^{45}$

\section{MitraClip use in functional versus degenerative MR}

The role of MitraClip therapy in patients with functional, as opposed to degenerative, MR remains unclear. This is an important distinction, as patients with functional MR have worse outcomes following surgery compared to degenerative MR. ${ }^{46}$ Interestingly, MVR and replacement appeared to have equivalent outcomes for functional MR patients in a recent randomized trial, despite earlier data suggesting superior outcomes for repair. ${ }^{47}$ However, an excess incidence of recurrent MR was noted at 1-year among patients undergoing MVR, raising the possibility that outcomes following MitraClip therapy may vary based on MR etiology. These data compare with the generally suboptimal outcomes of the Alfieri double-orifice repair without annuloplasty (which is most analogous to MitraClip therapy). ${ }^{40}$ Patients with functional MR undergoing surgery seem to fare better with an undersized annuloplasty added to Alfieri's techinique. ${ }^{48}$

To date, no randomized trial data have adequately addressed this issue. Initial studies lacked patients with this MR etiology. Only about one-quarter of patients in the EVEREST II randomized trial had functional MR; in contrast, $77.1 \%$ of patients in ACCESS-EU had functional MR. Though MitraClip therapy was inferior to surgery for patients overall in ACCESS-EU, a secondary intentionto-treat analysis showed that surgery was nonsuperior in patients with functional MR. ${ }^{32}$ Similar to ACCESS-EU, about three-quarters of patients in the GRASP registry (Grasso et al $)^{33}$ data had functional MR, and no significant differences were noted in primary efficacy end points between the two disease etiologies. Even among patients with the highest predicted surgical risks, no significant differences in outcome were seen between functional versus degenerative MR patients. ${ }^{36}$ At least one other small series has confirmed these findings. ${ }^{49}$ Two ongoing randomized trials (discussed later) will help clarify this important issue.

\section{Currently approved indications in the US}

In the US, Abbot Vascular's MitraClip system is currently approved by the Food and Drug Administration for patients with degenerative $\mathrm{MR} \geq 3+$ and symptoms (New York Heart Association functional class III or IV) who meet prohibitive risk criteria (30-day Society of Thoracic Surgeons predicted operative mortality risks of $\geq 8 \%$ for planned mitral valve replacement, or $\geq 6 \%$ for planned MVR; porcelain aorta; frailty; hostile chest; severe liver disease or cirrhosis; severe pulmonary hypertension with pressures two-thirds of systemic; as well as a list of unusual extenuating circumstances).${ }^{50}$ A patient's comorbidities must not preclude the expected benefit of reducing MR to $\leq 2+$.

\section{Ongoing trials}

Several ongoing trials will help clarify the role of MitraClip therapy in the treatment of functional MR. The COAPT trial (Clinical Outcomes Assessment of MitraClip Percutaneous Therapy), a prospective, randomized, parallel controlled study, is currently enrolling patients with $\geq 3+$ functional MR and heart failure (LVEF 20\%-50\%). A similar study, the RESHAPE-HF trial (Randomized Study of the MitraClip Device in Heart Failure Patients With Clinically Significant Functional Mitral Regurgitation), is enrolling patients with $\geq 3$ + functional MR and LVEF 15\%-40\% deemed nonsurgical candidates who will be randomized to MitraClip therapy versus medical management.

\section{Limitations of the MitraClip system}

The present MitraClip device does not address all of the aspect of mitral valve dysfunction resulting in MR. In particular, though it can improve leaflet coaptation, it cannot address 
the mitral annulus (as can be done surgically by suturing a ring in place to provide annular stabilization), nor can it address problems with the chordae tendinae (as can be done with PTFE neochordae). Though a number of technologies designed to improve annular geometry (eg, by placing a wire in the coronary sinus, which runs just posterior and lateral to the mitral annulus) or address chordal problems are under development, none have combined all the elements available to the surgeon in a single device.

\section{Conclusion}

As a logical extension of the Alfieri edge-to-edge MVR technique, the MitraClip percutaneous MVR technique has emerged as an option for mitral repair in high-risk surgical patients. Data from a variety of sources demonstrate that though the MitraClip system is less effective than surgical MVR intervention in most patients, it remains a safe alternative, which usually does not preclude future surgical options to address MR. In high-risk patients who are poor operative candidates, MitraClip has a favorable safety profile and can improve both the degree of MR and symptoms in the majority of patients in whom it is utilized. Ongoing trials will help to clarify the impact of MitraClip therapy on symptoms versus long-term survival among high-risk patients, as well as its role as a therapy in other patient populations, such as those with functional MR. The learning curve associated with MitraClip implantation suggests this therapy should be performed in centers of excellence with recognized surgical and structural expertise in mitral valve pathologies. In the future, effective percutaneous therapies for MR will have to incorporate features readily accomplished in open heart surgery, such as annular stabilization and repair of the subvalvular apparatus as needed. Reduction in MR to zero or trace will be requisite before percutaneous MVR can be considered a viable and equivalent alternative to surgery.

\section{Acknowledgments}

JTM is the Irene Piccinini Investigator in Cardiac Surgery Research at Johns Hopkins. TCC is the Hugh Sharp Fellow in Cardiac Surgery Research at Johns Hopkins.

\section{Disclosure}

The authors report no conflicts of interest in this work.

\section{References}

1. Block, PC. Percutaneous mitral valve repair for mitral regurgitation. J Interv Cardiol. 2003;16(1):93-96.

2. Enriquez-Sarano M, Schaff HV, Orszulak TA, Tajik AJ, Bailey KR, Frye RL. Valve repair improves the outcome of surgery for mitral regurgitation. A multivariate analysis. Circulation. 1995;91(4):1022-1028.
3. Moss RR, Humphries KH, Gao M, et al. Outcome of mitral valve repair or replacement: a comparison by propensity score analysis. Circulation. 2003;108(Suppl 1):II90-II97.

4. Deloche A, Jebara VA, Relland JY, et al. Valve repair with Carpentier techniques. The second decade. J Thorac Cardiovasc Surg. 1990;99(6):990-1001; discussion 1001-1002.

5. Carpentier A. Cardiac valve surgery-the "French correction". J Thorac Cardiovasc Surg. 1983;86(3):323-337.

6. Maisano F, Torracca L, Oppizzi M, et al. The edge-to-edge technique: a simplified method to correct mitral insufficiency. Eur J Cardiothorac Surg. 1998;13(3):240-245; discussion 245-246.

7. Maisano F, Schreuder JJ, Oppizzi M, Fiorani B, Fino C, Alfieri O. The double-orifice technique as a standardized approach to treat mitral regurgitation due to severe myxomatous disease: surgical technique. Eur J Cardiothorac Surg. 2000;17(3):201-205.

8. St Goar FG, Fann JI, Komtebedde J, et al. Endovascular edge-to-edge mitral valve repair: short-term results in a porcine model. Circulation. 2003;108(16):1990-1993.

9. Fann JI, St Goar F.G, Komtebedde J, et al. Beating heart catheter-based edge-to-edge mitral valve procedure in a porcine model: efficacy and healing response. Circulation. 2004;110(8):988-993.

10. Gillinov AM, Cosgrove DM. Mitral valve repair for degenerative disease. J Heart Valve Dis. 2002;11(Suppl 1):S15-S20.

11. Mihaileanu S, Marino JP, Chauvaud S, et al. Left ventricular outflow obstruction after mitral valve repair (Carpentier's technique). Proposed mechanisms of disease. Circulation. 1988;78(3 Pt 2): I78-184.

12. Seeburger J, Kuntze T, Mohr FW. Gore-tex chordoplasty in degenerative mitral valve repair. Semin Thorac Cardiovasc Surg. 2007;19(2): 111-115.

13. David TE. Artificial chordae. Semin Thorac Cardiovasc Surg. 2004; 16(2):161-168.

14. Salvador L, Mirone S, Bianchini R, et al. A 20-year experience with mitral valve repair with artificial chordae in 608 patients. $J$ Thorac Cardiovasc Surg. 2008;135(6):1280-1287.

15. Kobayashi J, Sasako Y, Bando K, Minatoya K, Niwaya K, Kitamura S. Ten-year experience of chordal replacement with expanded polytetrafluoroethylene in mitral valve repair. Circulation. 2000;102(19 Suppl 3): III30-III34.

16. Falk V, Seeburger J, Czesla M, et al. How does the use of polytetrafluoroethylene neochordae for posterior mitral valve prolapse (loop technique) compare with leaflet resection? A prospective randomized trial. J Thorac Cardiovasc Surg. 2008;136(5):1205; discussion 1205-1206.

17. Seeburger J, Falk V, Borger MA, et al. Chordae replacement versus resection for repair of isolated posterior mitral leaflet prolapse: a egalite. Ann Thorac Surg. 2009;87(6):1715-1720.

18. Seeburger J, Borger MA, Doll N, et al. Comparison of outcomes of minimally invasive mitral valve surgery for posterior, anterior and bileaflet prolapse. Eur J Cardiothorac Surg. 2009;36(3): $532-538$.

19. Yoo JS, Kim JB, Jung SH, et al. Mitral durability after robotic mitral valve repair: analysis of 200 consecutive mitral regurgitation repairs. J Thorac Cardiovasc Surg. 2014;148(6):2773-2779.

20. Ramzy D, Trento A, Cheng W, et al. Three hundred robotic-assisted mitral valve repairs: the Cedars-Sinai experience. J Thorac Cardiovasc Surg. 2014;147(1):228-235.

21. Murphy DA, Moss E, Binongo J, et al. The expanding role of endoscopic robotics in mitral valve surgery: 1,257 consecutive procedures. Ann Thorac Surg. 2015;100(5):1675-1681; discussion $1681-1682$.

22. Feldman T, Wasserman H.S, Herrmann H.C, et al. Percutaneous mitral valve repair using the edge-to-edge technique: six-month results of the EVEREST Phase I Clinical Trial. J Am Coll Cardiol. 2005;46(11):2134-2140.

23. Alegria-Barrero E, Chan P.H, Foin N, et al. Concept of the central clip: when to use one or two MitraClips(R). EuroIntervention. 2014;9(10):1217-1224. 
24. Feldman T, Kar S, Rinaldi M, et al. Percutaneous mitral repair with the MitraClip system: safety and midterm durability in the initial EVEREST (Endovascular Valve Edge-to-Edge REpair Study) cohort. J Am Coll Cardiol. 2009;54(8):686-694.

25. Mauri L, Garg P, Massaro JM, et al. The EVEREST II Trial: design and rationale for a randomized study of the evalve mitraclip system compared with mitral valve surgery for mitral regurgitation. Am Heart J. 2010;160(1):23-29.

26. Argenziano M, Skipper E, Heimansohn D, et al. Surgical revision after percutaneous mitral repair with the MitraClip device. Ann Thorac Surg. 2010;89(1):72-80; discussion p. 80.

27. Schillinger W, Athanasiou T, Weicken N, et al. Impact of the learning curve on outcomes after percutaneous mitral valve repair with MitraClip and lessons learned after the first 75 consecutive patients. Eur J Heart Fail. 2011;13(12):1331-1339.

28. Feldman T, Foster E, Glower DD, et al. Percutaneous repair or surgery for mitral regurgitation. $N$ Engl J Med. 2011;364(15):1395-1406.

29. Glower D, Ailawadi G, Argenziano M, et al. EVEREST II randomized clinical trial: predictors of mitral valve replacement in de novo surgery or after the MitraClip procedure. J Thorac Cardiovasc Surg. 2012; 143(4 Suppl):S60-S63.

30. Geidel S, Ostermeyer J, Lass M, Schmoeckel M. Complex surgical valve repair after failed percutaneous mitral intervention using the MitraClip device. Ann Thorac Surg. 2010;90(1):277-279.

31. Rogers JH, Yeo KK, Carroll JD, et al. Late surgical mitral valve repair after percutaneous repair with the MitraClip system. J Card Surg. 2009;24(6):677-681.

32. Maisano F, Franzen O, Baldus S, et al. Percutaneous mitral valve interventions in the real world: early and 1-year results from the ACCESS-EU, a prospective, multicenter, nonrandomized postapproval study of the MitraClip therapy in Europe. J Am Coll Cardiol. 2013;62(12):1052-1061.

33. Grasso C, Capodanno D, Scandura S, et al. One- and twelve-month safety and efficacy outcomes of patients undergoing edge-to-edge percutaneous mitral valve repair (from the GRASP Registry). Am J Cardiol. 2013;111(10):1482-1487.

34. Vakil K, Roukoz H, Sarraf M, et al. Safety and efficacy of the MitraClip(R) system for severe mitral regurgitation: a systematic review. Catheter Cardiovasc Interv. 2014;84(1):129-136.

35. Puls M, Lubos E, Boekstegers P, et al. One-year outcomes and predictors of mortality after MitraClip therapy in contemporary clinical practice: results from the German transcatheter mitral valve interventions registry. Eur Heart J. 2016;37(8):703-712.

36. Whitlow PL, Feldman T, Pedersen W.R, et al. Acute and 12-month results with catheter-based mitral valve leaflet repair: the EVEREST II (Endovascular Valve Edge-to-Edge Repair) High Risk Study. J Am Coll Cardiol. 2012;59(2):130-139.

37. Neuss M, Schau T, Schoepp M, et al. Patient selection criteria and midterm clinical outcome for MitraClip therapy in patients with severe mitral regurgitation and severe congestive heart failure. Eur J Heart Fail. 2013;15(7):786-795
38. Whitlow P. Percutaneous edge-to-edge evalve mitral evalve mitral valve repair in the US "High Risk" Registry, in Trancatheter Cardiovascular Therapeutics (TCT) meeting; 2009: San Francisco, CA.

39. Munkholm-Larsen S, Wan B, Tian DH, et al. A systematic review on the safety and efficacy of percutaneous edge-to-edge mitral valve repair with the MitraClip system for high surgical risk candidates. Heart. 2014;100(6):473-478.

40. Maisano F, Caldarola A, Blasio A, De Bonis M, La Canna G, Alfieri O. Midterm results of edge-to-edge mitral valve repair without annuloplasty. J Thorac Cardiovasc Surg. 2003;126(6):1987-1997.

41. Wu AH, Aaronson KD, Bolling SF, Pagani FD, Welch K, Koelling TM. Impact of mitral valve annuloplasty on mortality risk in patients with mitral regurgitation and left ventricular systolic dysfunction. J Am Coll Cardiol. 2005;45(3):381-387.

42. Giannini C, Fiorelli F, De Carlo M, et al. Comparison of percutaneous mitral valve repair versus conservative treatment in severe functional mitral regurgitation. Am J Cardiol. 2015;117(2):271-277.

43. Schueler R, Nickenig G, May AE, et al. Predictors for short-term outcomes of patients undergoing transcatheter mitral valve interventions: analysis of 778 prospective patients from the German TRAMI registry focusing on baseline renal function. EuroIntervention. Epub 2015 Sep 8;11(5).

44. Estevez-Loureiro R, Settergren M, Pighi M, et al. Effect of advanced chronic kidney disease in clinical and echocardiographic outcomes of patients treated with MitraClip system. Int J Cardiol. 2015;198:75-80.

45. Seifert M, Schau T, Schoepp M, Arya A, Neuss M, Butter C. MitraClip in CRT non-responders with severe mitral regurgitation. Int J Cardiol. 2014;177(1):79-85.

46. Jensen H, Jensen MO, Nielsen SL. Surgical treatment of functional ischemic mitral regurgitation. J Heart Valve Dis. 2015;24(1):30-42.

47. Acker MA, Parides MK, Perrault LP, et al. Mitral-valve repair versus replacement for severe ischemic mitral regurgitation. $N$ Engl J Med. 2014;370(1):23-32.

48. De Bonis M, Lapenna E, La Canna G, et al. Mitral valve repair for functional mitral regurgitation in end-stage dilated cardiomyopathy: role of the "edge-to-edge" technique. Circulation. 2005;112(9 Suppl): I402-408.

49. Braun D, Lesevic H, Orban M, et al. Percutaneous edge-to-edge repair of the mitral valve in patients with degenerative versus functional mitral regurgitation. Catheter Cardiovasc Interv. 2014;84(1):137-146.

50. Group A. MitraClip Transcatheter Mitral Valve Repair: Frequently Asked Questions; 2015; December 19, 2015. Available from: http:// www.mitraclip.com/hcp/faqs.
Medical Devices: Evidence and Research

\section{Publish your work in this journal}

Medical Devices: Evidence and Research is an international, peerreviewed, open access journal that focuses on the evidence, technology, research, and expert opinion supporting the use and application of medical devices in the diagnosis, treatment and management of clinical conditions and physiological processes. The identification of novel

\section{Dovepress}

devices and optimal use of existing devices which will lead to improved clinical outcomes and more effective patient management and safety is a key feature. The manuscript management system is completely online and includes a quick and fair peer-review system. Visit http://www. dovepress.com/testimonials.php to read real quotes from authors. 